\title{
Universidad pública y desarrollo: innovación, inclusión y democratización del conocimiento
}

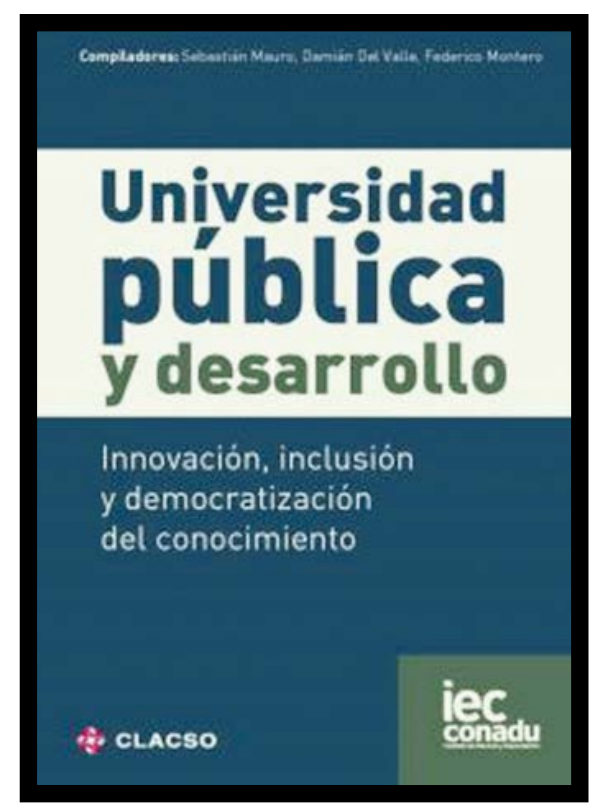

Universidad pública y desarrollo: innovación, inclusión y democratización del conocimiento / Aldo Ferrer et al.; compilado por Sebastián Mauro; Damián Del Valle; Federico Montero; editado por Miriam Socolovsky; 1a ed. - Buenos Aires: IEC - CONADU; Ciudad Autónoma de Buenos Aires: CLACSO, 2015. Libro digital, PDF

La recuperación de la centralidad del Estado en su capacidad regulatoria, distributiva $y$ en la provisión de bienes y servicios públicos ha interpelado al sistema científico y a la Universidad Pública. La Universidad se ha visto obligada a repensar las históricas misiones de docencia, investigación y extensión en el marco de una agenda de reformas políticas y sociales orientadas a la generación de un proceso de desarrollo con equidad.

Se trata de un escenario novedoso, en el cual se ha revitalizado el debate sobre la relación entre tres actores disociados durante el auge de las políticas neoliberales: el sistema científico, el Estado y el aparato productivo. En el campo de las ciencias sociales, este escenario obliga a revisar las culturas académicas e institucionales instaladas, y repensar la necesidad de construir conocimiento socialmente relevante y de ampliar su impacto. Visibilizar, multiplicar y promover prácticas de vinculación desde nuestros campos disciplinares ha significado uno de los grandes desafíos de los últimos años. En ese marco, la Facultad de Ciencias Sociales de la Universidad de Buenos Aires se ha propuesto trabajar fuertemente para generar aportes activos $y$ concretos a las transformaciones estructurales que se están produciendo tanto en la sociedad como con el Estado. La vinculación con FEDUBA, sindicato de docentes universitarios de la UBA, para el diseño y organización del Programa en Investigación, Transferencia y Desarrollo en la Universidad Pública constituye una de estas iniciativas.

Como ha señalado el recordado Profesor Pedro Krotsch, quien fue director del Instituto Gino Germani y uno de los primeros pensadores de la universidad pública en América Latina: "La universidad debe poder retraducir las 
problemáticas del campo social, político y cultural a la lógica del campo universitario, que es el campo de la producción del conocimiento. La universidad debe pensarse con responsabilidad política, atenta a las necesidades sociales pero desde su propia naturaleza".

Del Prólogo de Glenn Postolski y Patricia Funes 